\title{
Reviewing the Optimizing Techniques for the Turning Operation of Different Specimen and its various significant Cutting Parameters affecting Surface Roughness using Taguchi Method
}

\author{
Er. Gurupreet Singh ${ }^{1}$, SardarCharan Singh ${ }^{2}$ and Hardeep Singh Maan ${ }^{3}$ \\ ${ }^{I}$ Mechanical Engineer, Operations (Warranty Team), Cardekho.Com, Gurgaon, Haryana \\ ${ }^{2}$ Technical Head ( Retd.), Bihar Police Wireless, Muzaffarpur, Bihar \\ ${ }^{3}$ Asst.Prof., Dept. of mechanical engineering, GD Goenka University, Gurgaon, Haryana
}

\begin{abstract}
A series of experiments were done to find the effect of the cutting parameters on the surface roughness in a turning operation since 1975. To obtain the prediction equation of the surface roughness, 81 experiments were carried out at three levels for each independent variable to develop a second-order model. Taguchi method was used for the execution of the plan of experiments, for three factors at three levels.The contribution order of the cutting parameters for surface roughness is feed rate, then depth of cut, and then cutting speed. The cutting speed and workpiece diameter had greater influence on roughness.

Regression analysis is considered to be one of the most important data mining techniques. The correlation between workpiece hardness, point angle, depth of cut, and spindle speed has a significant impact on the surface roughness independently. Four interactions among these five variables also significantly affect the surface roughness model as follows: - The main result of the study was cutting speed, feed, point angle, depth of cut and cutting time significantly affect the surface roughness independently. The experimental result analysis showed that the combination of higher levels of cutting speed, depth of cut, and nose radius and lower level of feed is essential to achieve simultaneous maximization of material removal rate and minimization of surface roughness.
\end{abstract}

Keywords: Turning operations, Cutting parameters, Taguchi method, Regression analysis, Data mining techniques.

\section{Introduction}

To obtain the prediction equation of the surface roughness, 81 experiments were carried out at three levels for each independent variable to develop a second-order model. A series of bars were prepared from 63.5$152.4 \mathrm{~mm}$ diameter materials. Nine bars were used, each being divided into ten blanks. Each of the test bars was cut with a new part of the tool cutting edge. The workpiece was removed from the machine and the surface measured parallel and perpendicular to the tool grooves by a Talysurfsurface roughness measuring instrument. Values used in the results are the average of five readings taken at equal intervals around the workpiece. A pen recording was also taken of the surface profile along the feed marks. The 'Peak to Valley' height was measured from the recorded profile curves of the surface finish.

The main results of that study was the cutting parameter which affects roughness most is the feed rate and depth of cut has little effect on the surface roughness. As cutting speed and tool nose radius increase, surface roughness also decreases. As the feed rate increases surface roughness increases.

In this research review of experiments were conducted and new results were found which was quite surprising and optimised also. Review of Taguchi method, regression analysis, impact of different parameters and surface roughness were observed.

Taguchi method was used for the execution of the plan of experiments, for three factors at three levels. An FFT Analyser was used to measure tool vibrations in radial and feed directions. The surface roughness was measured using a Surtronic 3+ measuring instrument.

To establish the prediction model, regression analysis is conducted with MINITAB using the above experimental data. Regression analysis is considered to be one of the most important and most popularly used data mining techniques. The correlation between workpiece hardness, point angle, depth of cut, and spindle speed has a significant impact on the surface roughness independently. A multi-characteristics response optimization model based on Taguchi and Utility concept is used to optimize process parameters, such as speed, feed, depth of cut, and nose radius on multiple performance characteristics, namely, surface roughness and material removal rate during turning of AISI 202 austenitic stainless steel using a CVD coated cemented carbide tool. Taguchi's L8 orthogonal array $(\mathrm{OA})$ is selected for experimental planning. 


\section{Materials And Methods}

The equipment used for turning was saddle type turret lathe equipped with a $10 \mathrm{HP}$ variable speed motor and a modified variable feed. The workpiece used was mild carbon steel (SAE 1020) ranging in size from $63.5 \mathrm{~mm}$ to $152.4 \mathrm{~mm}$ diameter. These diameters made it possible to obtain surface speeds up to $1000 \mathrm{ft} / \mathrm{min}$. The cutting tool had tungsten carbide disposable inserts. The inserts used had a $5^{\circ}$ positive back rake.

To obtain the prediction equation of the surface roughness, 81 experiments were carried out at three levels for each independent variable to develop a second-order model. A series of bars were prepared from 63.5$152.4 \mathrm{~mm}$ diameter materials. Nine bars were used, each being divided into ten blanks. Each of the test bars was cut with a new part of the tool cutting edge. The workpiece was removed from the machine and the surface measured parallel and perpendicular to the tool grooves by a Talysurf surface roughness measuring instrument. Values used in the results are the average of five readings taken at equal intervals around the workpiece. A pen recording was also taken of the surface profile along the feed marks. The 'Peak to Valley' height was measured from the recorded profile curves of the surface finish.

Taguchi method is used to optimize the turning operation of S45C steel bars using tungsten carbide cutting tools and reported that cutting speed, feed rate, and depth of cut are the significant cutting parameters for affecting surface roughness. . The cutting test were made on a $6 \mathrm{~kW}$ lathe. The material used in the tests for controlled machining was free machining steel, $9 \mathrm{SMnPb} 28 \mathrm{k}$. The geometry of experiment of the workpiece allowed its fixation with a length of $15 \mathrm{~mm}$. cemented carbides inserts were used for machining. The used tool geometry was rake angle $6^{\circ}$ (positive), $5^{\circ}$ clearance angle and $0^{\circ}$ cutting edge inclination angle. The measurements were made over the turning surfaces using Profilometer S 6P.

Taguchi method was used for the execution of the plan of experiments, for three factors at three levels. The chosen array was the $\mathrm{L}_{27}\left(3^{13}\right)$, which has 27 rows corresponding to number of tests with 13 columns at three levels.

An FFT analyzer was used to measure tool vibrations in radial and feed directions. The surface roughness was measured using a Surtronic 3+ measuring instrument.

An SV 18 universal turning machine tool was used in experiments. The workpiece material was free cutting steel. The cemented carbides throw away inserts were used in experiments. The inserts type was TPGN 160304 for tool nose radius $0.4 \mathrm{~mm}$ and TPGN 160312 for tool nose radius $1.2 \mathrm{~mm}$. the approach angle $(\check{\mathrm{N}})$ was $90^{\circ}$ for shank type PTGNR/L 2525M16 and $45^{\circ}$ for PTGNR/L 2525M22.

An empirical model for the prediction of surface roughness in finish turning. The model considers the working parameters: workpiece hardness (material); feed; cutting tool point angle; depth of cut; spindle speed; and cutting time. One of the most important data mining techniques, nonlinear regression analysis with logarithmic data transformation, is applied in developing the empirical model. The values of surface roughness predicted by this model are then verified with extra experiments and compared with those from some of the representative models in the literature. Metal cutting experiments and statistical tests demonstrate that the model developed in this work produces smaller errors than those from some of the existing models and have a satisfactory goodness in both model construction and verification.

These experiments are conducted on a production type YAM CK-1 CNC Lathe with a FANUC OT10 controller. When collecting the surface roughness data of the shaft with surface profilometerMitutoyo Surface Tester SJ-03, three measurements are taken along the shaft axis for each sample and each is about $120^{\circ} \square$ apart. Based on the recommendation from ASME B46.1-1995 [25], a probe radius of $10 \mu \mathrm{m}$ (diamond) is used. The carbide inserts have a multiphase coating with $\mathrm{Ti}(\mathrm{C}, \mathrm{N}), \mathrm{Al} 2 \mathrm{O} 3$, and TiN (Carboloy grade TP200). The length (hang) and diameter of the starting block is $76.200 \mathrm{~mm}$ and $31.750 \mathrm{~mm}$. The nose radius is fixed at $0.819 \mathrm{~mm}$.

They assume that the three, four and five-factor interactions were negligible, because these higher-order interactions were normally assumed to be almost impossible in practice. Therefore, a $2^{5-1}$ fractional design was selected. This resolution $\mathrm{V}$ design leads to 16 runs of the experiments. To consider system variations, such as tool wear and vibration in particular, the cutting time and a replicate number of three are selected, respectively. As a result, the total number of experiments was 48 .

To establish the prediction model, regression analysis is conducted with MINITAB using the above experimental data. Regression analysis is considered to be one of the most important and most popularly used data mining techniques. The correlation between work piece hardness, point angle, depth of cut, and spindle speed has a significant impact on the surface roughness independently.

Taguchi method is used to find optimum cutting parameters for surface roughness and cutting force in end milling when machining hardened steel AISI H13 with TiN coated P10 carbide insert tool under semifinishing and finishing conditions of high speed cutting. The milling parameters evaluated are cutting speed, feed rate, and depth of cut. In end milling, use of high cutting speed, low feed rate and low depth of cut are recommended to obtain better surface roughness and low cutting force. 
Turning tests is done to determine optimum machining parameters for machining of austenitic stainless steel. In the machining of AISI 304 austenitic Stainless steels, optimum cutting speed lead to lowest tool flank wear. Tool flank wear decreased with increasing the cutting speed up to $180 \mathrm{~m} / \mathrm{min}$.

Machining characteristics of austenitic stainless steels (AISI 304 and AISI 316) using CVD multi-layer coated carbide tools. The turning tests were conducted at four different cutting speeds with a constant feed rate and depth of cut. The influence of work piece grade, cutting tool coating top layer and cutting speed were investigated on cutting forces and machined surface roughness. With increasing cutting speed surface finish values decreased until a minimum value was reached, beyond which they increased.

Taguchi method is used for surface finish optimization in end milling of Aluminium blocks. The experimental results indicate that in this study the effects of spindle speed and feed rate on surface finish were larger than depth of cut for milling operation.

Taguchioptimization methodology is applied to optimize cutting parametersinturning Ti-6\% Al-4\%V extra low interstitial with coated and uncoated cemented carbide tools under dry cutting condition and high cutting speed. Theturningparameters evaluated are cutting speed of 55,75 , and $95 \mathrm{~m} / \mathrm{min}$, feed rate of $0.15,0.25$ and $0.35 \mathrm{~mm} / \mathrm{rev}$, depth of cut of $0.10,0.15$ and $0.20 \mathrm{~mm}$ and tool grades of K313, KC9225 and KC5010, each at three levels. The analysis of results show that the optimal combination ofparameters are at cutting speed of 75 $\mathrm{m} / \mathrm{min}$, feed rate of $0.15 \mathrm{~mm} / \mathrm{min}$, depth of cut of $0.10 \mathrm{~mm}$ and tool grade of KC 9225 . The cutting speed and tool grade have a significant effect on surface roughness are 0.000 and have a contribution are $47.146 \%$ and $38.881 \%$, respectively. At optimal condition, contribution of each cutting parameter on surface roughness is reached at 20.47 from tool grade, 21.01 from feed rate, 11.54 from depth of cut and 11.17 from cutting speed.

RCGA approach is quite advantageous in order to have the minimum surface roughness values, and their corresponding optimum cutting parameters, for certain constraints.

The experimental investigation presented here was carried out on a Kirloskar lathe with $5 \mathrm{~kW}$ power rating. The workpiece used for investigation was AISI 1045 steel, with chemical composition of $0.5 \%$ carbon, $0.15 \%$ silicon, $0.6 \%$ manganese, $0.05 \%$ sulphur and $0.04 \%$ phosphorus. AISI 1045 steels are most commonly used for all forms of close tolerance shafting, e.g. hydraulic shaft, pump shaft, piston rods, sprockets and springs, cylinders, cams, crank shafts, keys, small arm parts, etc. A precisely prepared machined ground and polished shafting, seam free surface finish is first induction hardened to a case depth of 1.27-2.28 mm resulting in a minimum surface hardness of approximately Rockwell C 50. This imparts the necessary properties to the bar as the extra hardness ensures superior wear resistance. The bars are hard chromed in the same manner as chrome plated shafting thus allowing the same advantageous corrosion and wear resistance, but with the induction hardening, the bars give superior service. This necessitates the requirement of a high finished product.In this experiment, in order to investigate the surface finish of the machined work piece and machine tool power consumption, during cutting of the AISI 1045 steel, a multilayered coated (TiC and TiN) tungsten carbide tool was used.

A fully factorial experiment uses all the possible combinations of a number of factors at their respective test levels to arrive at an outcome. But more efficient test plans, as developed by statisticians, fractional factorial experiments (FFEs) use only a portion of the total combinations to estimate the main factor effects and some, not all, of the interactions. Certain treatment conditions are chosen to maintain the orthogonality among the various factors and interactions.

According to Taguchi, depending upon number of levels in a factor, a 2 or a 3 level Orthogonal Array (OA) can be selected. In this situation a possible matrix is a 16 trial OA which is labeled as L16 matrix. One can observe that there are 15 columns in this array which may have a factor assigned to each column. The 16 trials provide 15 degrees of freedoms (DOFs) for the entire experiment allocated to 15 columns of two levels, each column with one DOF. Such an array allows all the error DOFs to be traded for factor DOFs and provide the particular test combinations that accommodate that approach.

Saeed ZareChavoshi\& Mehdi Tajdari (2009) [25] develop a surface roughness model in hard turning operation of AISI 4140 using CBN cutting tool. Turning process of hard steels with hardness above $45 \mathrm{HRC}$ is called hard turning.

A multi-characteristics response optimization model based on Taguchi and Utility concept is used to optimize process parameters, such as speed, feed, depth of cut, and nose radius on multiple performance characteristics, namely, surface roughness and material removal rate during turning of AISI 202 austenitic stainless steel using a CVD coated cemented carbide tool. Taguchi's L8 orthogonal array (OA) is selected for experimental planning.

\section{Discussions And Results}

The experimental result analysis showed that the combination of higher levels of cutting speed, depth of cut, and nose radius and lower level of feed is essential to achieve simultaneous maximization of material removal rate and minimization of surface roughness. 
The main results of the study was the cutting parameter which affects roughness most is the feed rate and depth of cut has little effect on the surface roughness. As cutting speed and tool nose radius increase, surface roughness also decreases. As the feed rate increases surface roughness increases.

The surface roughness and tool vibration data during turning of mild steel at different levels were investigated.

A systematic procedure of using Taguchi parameter design in process control in order to identify the optimum surface roughness performance with a particular combination of cutting parameters in an end milling operation was demonstrated.

The correlation between cutting conditions and the roughness evaluating parameters was established.

Cutting speed and work piece diameter has greater influence on roughness followed by feed. The depth of cut has no significant influence on roughness.

The machining parameters influence and levels that provide sufficient robustness of the machining process towards the achievement of the desired surface roughness for cold pre-formed steel workpieces in fine turning was described.

Effects of free cutting additives such as $\mathrm{S}, \mathrm{Ca}, \mathrm{Cu}$ and $\mathrm{Bi}$ on the machinability of work materials SUS303, SUS303Cu, SUS304 and SUS316 were found.

Taguchioptimization methodology is applied to optimize cutting parametersinturning Ti-6\% $\mathrm{Al}-4 \% \mathrm{~V}$ extra low interstitial with coated and uncoated cemented carbide tools under dry cutting condition and high cutting speed. Theturningparameters evaluated are cutting speed of 55,75 , and $95 \mathrm{~m} / \mathrm{min}$, feed rate of $0.15,0.25$ and $0.35 \mathrm{~mm} / \mathrm{rev}$, depth of cut of $0.10,0.15$ and $0.20 \mathrm{~mm}$ and tool grades of K313, KC9225 and KC5010, each at three levels. The analysis of results show that the optimal combination ofparameters are at cutting speed of 75 $\mathrm{m} / \mathrm{min}$, feed rate of $0.15 \mathrm{~mm} / \mathrm{min}$, depth of cut of $0.10 \mathrm{~mm}$ and tool grade of KC9225. The cutting speed and tool grade have a significant effect on surface roughness are 0.000 and have a contribution are $47.146 \%$ and $38.881 \%$, respectively. At optimal condition, contribution of each cutting parameter on surface roughness is reached at 20.47 from tool grade, 21.01 from feed rate, 11.54 from depth of cut and 11.17 from cutting speed. The effect of cutting parameters on surface finish and power consumption during high speed machining of AISI 1045 steel was estimated.

A fully factorial experiment uses all the possible combinations of a number of factors at their respective test levels to arrive at an outcome. But more efficient test plans, as developed by statisticians, fractional factorial experiments (FFEs) use only a portion of the total combinations to estimate the main factor effects and some, not all, of the interactions. Certain treatment conditions are chosen to maintain the orthogonality among the various factors and interactions.

According to Taguchi, depending upon number of levels in a factor, a 2 or a 3 level Orthogonal Array (OA) can be selected. In this situation a possible matrix is a 16 trial OA which is labeled as L16 matrix. One can observe that there are 15 columns in this array which may have a factor assigned to each column. The 16 trials provide 15 degrees of freedoms (DOFs) for the entire experiment allocated to 15 columns of two levels, each column with one DOF. Such an array allows all the error DOFs to be traded for factor DOFs and provide the particular test combinations that accommodate that approach.

The main result of the study was cutting speed had greater influence on surface roughness followed by feed. Cutting speed was again observed as most significant factor for power consumption followed by depth of cut.

\section{Conclusion}

The depth of cut had the most significant effect on surface roughness, followed by the feed rate and, finally, the cutting speed. Namely, the cutting speed had a little effect on machining. The surface roughness decreases with increasing the cutting speed and decreasing the depth of cut and the feed rate.

The experimental result analysis showed that the combination of higher levels of cutting speed, depth of cut, and nose radius and lower level of feed is essential to achieve simultaneous maximization of material removal rate and minimization of surface roughness. 


\section{References}

[1]. M. Hasegawa, A. Seireg and R. A. Lindberg (1975):Effect of the cutting parameters on the surface roughness in a turning operation.

[2]. Beauchamp \& co-workers (1996): The surface roughness and tool vibration data during turning of mild steel at different levels.

[3]. Yang et al. (1998): Taguchi method to optimize the turning operation of S45C steel bars using tungsten carbide cutting tool.

[4]. John et al. (2001): Systematic procedure of using Taguchi parameter design in processcontrol in order to identify the optimum surface roughness.

[5]. J. Paulo Damin (2001): Correlation between cutting conditions and the roughness evaluating parameters.

[6]. O.B. Abouelatta and J. Madl (2001): A surface roughness prediction model between cutting parameters and tool vibrations.

[7]. C. X. (Jack) Feng and X. Wang (2002): An empirical model for the prediction of surface roughness in finish turning.

[8]. Kopacet al. (2002): Machining parameters influence and levels that provide sufficient robustness of the machining process

[9]. Akasawa et al. (2003): Effects of free cutting additives.

[10]. Ghani et al. (2004): Taguchi method to find optimum cutting parameters for surface roughness and cutting force in end milling.

[11]. I Ciftci (2006): Machining characteristics of austenitic stainless steels (AISI 304 and AISI 316) using CVD multi layer coated carbide tools.

[12]. K. Palanikumar et al. (2006): Main machining parameters in metal turning operations are cutting speed, feed rate and depth of cut etc.

[13]. Nalbant et al. (2007): Taguchi method to find optimum cutting parameters for surface roughness in turning of AISI 1030 carbon steel bars.

[14]. Zhang et al. (2007): Taguchi method for surface finish optimization in end milling of Aluminum blocks

[15]. Akhyar et al. (2008): Taguchioptimization methodology.

[16]. T. Srikanth and V. kamala (2008): RCGA approach for optimization of cutting parameters in turning.

[17]. Anirban Bhattacharya et al. (2009): Effect of cutting parameters on surface finish and power consumption during high speed machining of AISI 1045 steel.

[18]. Saeed ZareChavoshi\& Mehdi Tajdari (2009): A surface roughness model in hard turning operation of AISI 4140 using CBN cutting tool. 